\section{Elasticity of torn supraspinatus tendons measured by shear wave elastography: a potential surrogate marker of chronicity?}

\author{
Seung-Jin Yoo', Seunghun Lee', Yoonah Song ${ }^{1}$, Chun Ki Kim², Bong Gun Lee ${ }^{3}$, Jiyoon Bae ${ }^{4}$ \\ Departments of ${ }^{1}$ Radiology, ${ }^{2}$ Nuclear Medicine, and ${ }^{3}$ Orthopedic Surgery, Hanyang University \\ College of Medicine, Seoul; ${ }^{4}$ Department of Pathology, National Police Hospital, Seoul, Korea
}

Purpose: This study investigated whether shear wave elastography (SWE) could be used to estimate the chronicity of supraspinatus tendon (SST) tears.

Methods: A retrospective study was performed. From November 2015 to July 2016, 113 patients (52 men, 61 women; age range, 21 to 79 years) with persistent shoulder pain underwent 119 rotator cuff tendon examinations by routine B-mode ultrasonography, while SST elasticity was measured using SWE. Following the exclusion of eight suboptimal examinations, four examinations with missing SST measurements, and 27 examinations of patients with other conditions, 80 examinations were analyzed. A torn SST was found in 54 examinations (27 with a partial-thickness tear and 27 with a full-thickness tear). Elasticity values were compared in multiple ways. The results were analyzed using the Mann-Whitney $\mathrm{U}$ test or Kruskal-Wallis test.

Results: No statistically significant difference in elasticity values (in $\mathrm{kPa}$ ) was found between normal (median, 94.65; interquartile range [IQR], 87.43 to 105.47) and torn SSTs (median, 96.79; IQR, 86.71 to 108.56) or between full-thickness tears (median, 93.80; IQR, 82.50 to 108.33 ) and partial-thickness tears (median, $96.83 ; \mathrm{IQR}, 90.60$ to 112.20). However, there was a statistically significant difference in elasticity according to whether the duration of symptoms was 1 year or less (median, 92.20; IQR, 84.01 to 104.38) or longer than 1 year (median, 105.10; IQR, 100.41 to $116.03 ; P=0.032$ ).

Conclusion: Elasticity values were significantly higher in torn SSTs in patients with chronic shoulder pain that had persisted for more than 1 year. Further studies with larger samples seem warranted to determine whether elasticity values measured by SWE can be used preoperatively as a surrogate marker of the chronicity of a rotator cuff tendon tear.

Keywords: Elasticity imaging techniques; Sonoelastography; Elastography; Rotator cuff injuries; Ultrasonography

\section{Introduction}

The supraspinatus tendon (SST) is the most commonly injured tendon of the rotator cuff [1]. Rotator cuff tendon tears are usually evaluated using magnetic resonance imaging (MRI), computed tomography (CT), and ultrasonography (US). US is an easily accessible and cost-effective imaging

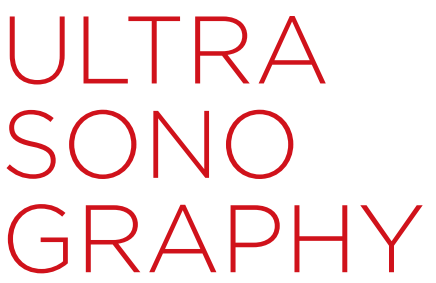

\section{ORIGINAL ARTICLE}

https://doi.org/10.14366/usg. 19035 pISSN: 2288-5919 - elSSN: 2288-5943 Ultrasonography 2020;39:144-151

Received: June 18, 2019

Revised: December 29, 2019

Accepted: January 2, 2020

Correspondence to:

Seunghun Lee, MD, Department of Radiology, Hanyang University Hospital, 222-1 Wangsimni-ro, Seongdong-gu, Seoul 04763, Korea

Tel. +82-2-2290-9163

Fax. +82-2-2293-2111

E-mail: radsh@hanyang.ac.kr

This is an Open Access article distributed under the terms of the Creative Commons Attribution NonCommercial License (http://creativecommons.org/ licenses/by-nc/4.0/) which permits unrestricted noncommercial use, distribution, and reproduction in any medium, provided the original work is properly cited.

Copyright @ 2020 Korean Society of Ultrasound in Medicine (KSUM)

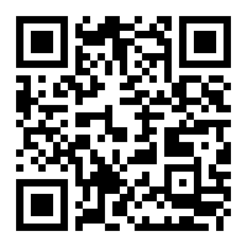

How to cite this article:

Yoo SJ, Lee S, Song Y, Kim CK, Lee BG, Bae J. Elasticity of torn supraspinatus tendons measured by shear wave elastography: a potential surrogate marker of chronicity? Ultrasonography. 2020 Apr;39(2):144-151. 
modality that can effectively detect tears in rotator cuff tendons; however, it has limitations in assessing the chronicity of tears and the elasticity of the tendon [2].

Shear wave elastography (SWE) is a novel emerging functional imaging modality that can quantify the elasticity value of various tissues with good reproducibility [3]. The term "higher elasticity value" used in this article corresponds to greater stiffness. SWE is already widely used in various clinical settings, such as to detect breast cancer [4], to evaluate liver fibrosis [5], and to characterize thyroid nodules [6]. Several studies have also employed SWE for superficial tendons, such as the Achilles or patellar tendons $[7,8]$. For example, Chen et al. [7] found lower elasticity values (i.e., less stiffness) in acutely ruptured Achilles tendons than in normal Achilles tendons using SWE. However, SWE has not as widely been applied to assess other musculoskeletal disorders. In particular, studies of deep tissue are scarce.

Chronic tears of the rotator cuff tendon result in adverse chronic changes, such as fatty degeneration and atrophy of rotator cuff muscles, tendon retraction, and inelasticity $[9,10]$. Torn tendons with chronic changes make surgical treatment more difficult and are associated with poor postoperative outcomes $[9,11]$. Therefore, a preoperative determination of whether a torn rotator cuff tendon has irreversible chronic changes can assist the surgeon in making a treatment decision (e.g., surgical vs. conservative treatment) [11].

Torn tendons undergo a 3-phase healing process that includes an inflammatory phase, a repair phase, and a remodeling phase [12]. In the remodeling phase, which occurs approximately 6 weeks after the injury, the amount of collagen in the tendon decreases, and repaired tissue changes into fibrous tissue and then into scar-like tendon tissue $[12,13]$. Therefore, torn tendons are likely to become stiffer as they become more chronic.

While the absence of symptoms or the presence of acute symptoms in patients with SST tears does not necessarily exclude chronicity, it seems logical to assume that SST tears associated with a longer duration of symptoms would more likely represent chronic tears than those with a shorter duration of symptoms. With that in mind, we hypothesized that SWE would yield higher measurements of elasticity values (i.e., greater stiffness) for SST tears with chronic symptoms than for tears with acute symptoms.

\section{Materials and Methods}

\section{Study Population}

This retrospective study was approved by the Institutional Review Board, and informed consent was waived.

Our study included 113 consecutive patients (52 men and 61 women; age range, 21 to 79 years) who underwent US evaluations from November 2015 to July 2016 for the evaluation of shoulder pain. None of them had a prior history of shoulder surgery. These 113 patients underwent 119 examinations (including bilateral shoulder examinations in four patients and a follow-up examination of a shoulder in two patients) of the rotator cuff tendon by routine B-mode US and SWE on the symptomatic shoulder. Of the 119 examinations, 39 were excluded from this study due to inconsistent sizes of the region of interest in eight, absence of elasticity measurements of the SST in four (omission of the measurement in one case and inability to obtain a measurement in three cases with massive tears), and various other conditions in 27 patients without an SST tear, including subacromial-subdeltoid bursitis, biceps long head tendon subluxation or rupture, Hill-Sachs lesion, subscapularis tendon tear, calcific tendinitis or tendinopathy without an SST tear, or avulsion fracture of the greater tuberosity.

Of the 80 examinations, no abnormal findings were found in 26 examinations performed in 26 patients ( 13 men and 13 women; age range, 23 to 69 years). The remaining 54 examinations, including two follow-up examinations of the same shoulder, performed in 52 patients ( 25 men and 27 women; age range, 38 to 79 years) showed an SST tear; 27 with a partial-thickness tear (focal, partial, or near full) and 27 with a full-thickness tear (including one case of a massive tear) (Fig. 1).

\section{Examination Protocol}

Every patient underwent a routine rotator cuff tendon evaluation using B-mode US on the symptomatic shoulder. During the examination, the elasticity value of the SST of the same shoulder was measured using real-time SWE (AixPlorer, Supersonic Imagine, Aix-en-Provence, France). The elasticity value of the SST was measured in the long-axis view with a linear array transducer (4-15 $\mathrm{MHz}$ ). B-mode US and SWE were performed by one of two boardcertified radiologists with 12 or 5 years of experience, respectively, in musculoskeletal sonography.

Patients were seated on a stool during US examinations of the rotator cuff tendons, which tendons were examined in both the long and short axes. The biceps long head tendon, subscapularis tendon, SST, and infraspinatus tendon were examined sequentially. The patient remained seated on a stool with a palm placed on the buttock and a flexed elbow pointing backward while the SST elasticity value was measured by gently placing the linear probe on the shoulder, parallel to the long axis of the SST, with minimal pressure applied to the tissue. When Q-box colorization was relatively homogeneous, the elasticity value was measured by placing a region of interest measuring $1 \mathrm{~mm}$ in diameter on the visible stump and/or retracted portion of the torn tendon (Fig. 2). In three patients with a massive tear, the residual SST was invisible 
on B-mode US examination; therefore, SST elasticity could not be measured. Those examinations were excluded, as mentioned above. The B-mode US and measured elasticity values were reviewed by two radiologists. Extremely high elasticity values measured in a generally red Q-box were excluded by consensus; these erroneous measurements were caused by the operator's manual compression of the tendon, which was inevitable in some cases due to the patient's position or pain. Low measurements at the edge of the torn tendon were considered to reflect contamination by joint effusion and were therefore also excluded. The average of the measured elasticity values was used for analysis.

\section{Data and Statistical Analysis}

To compare the elasticity values in various groups, 54 examinations

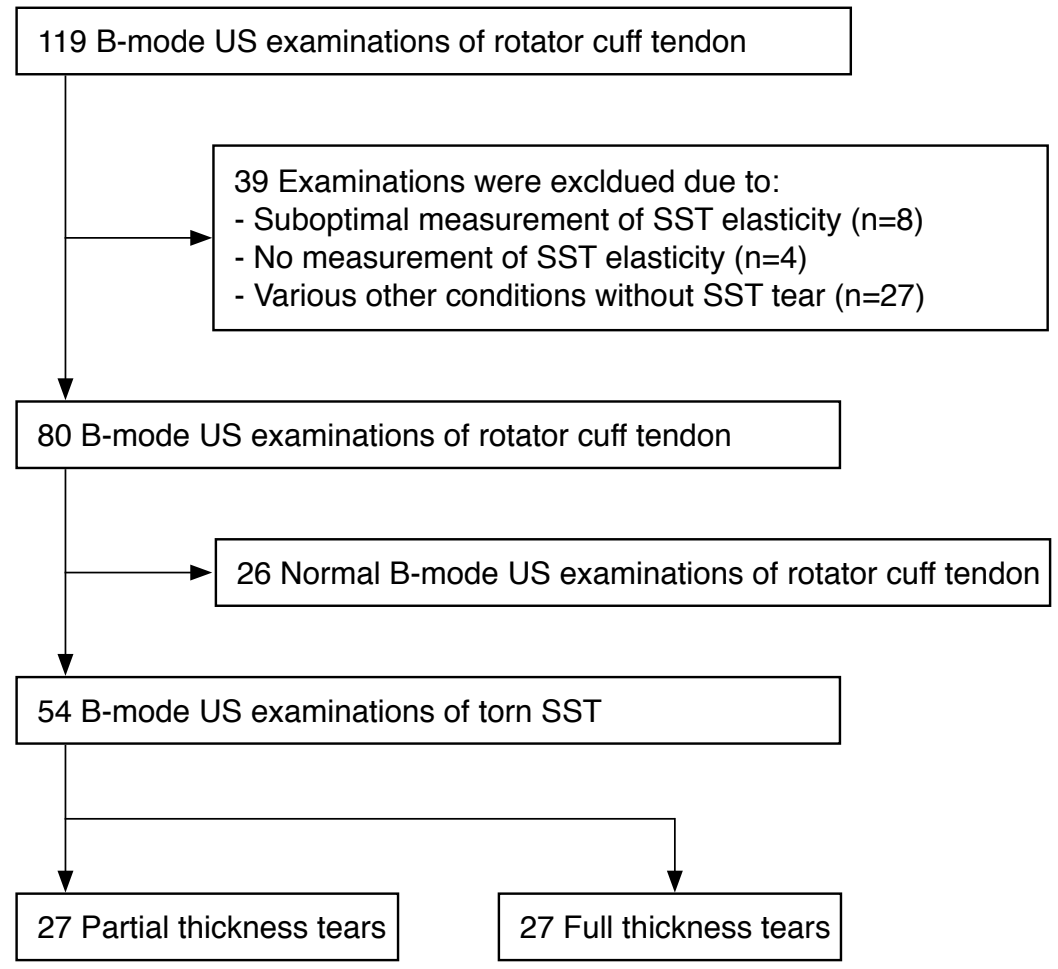

Fig. 1. Flow chart of patients included in the study. US, ultrasonography; SST, supraspinatus tendon.

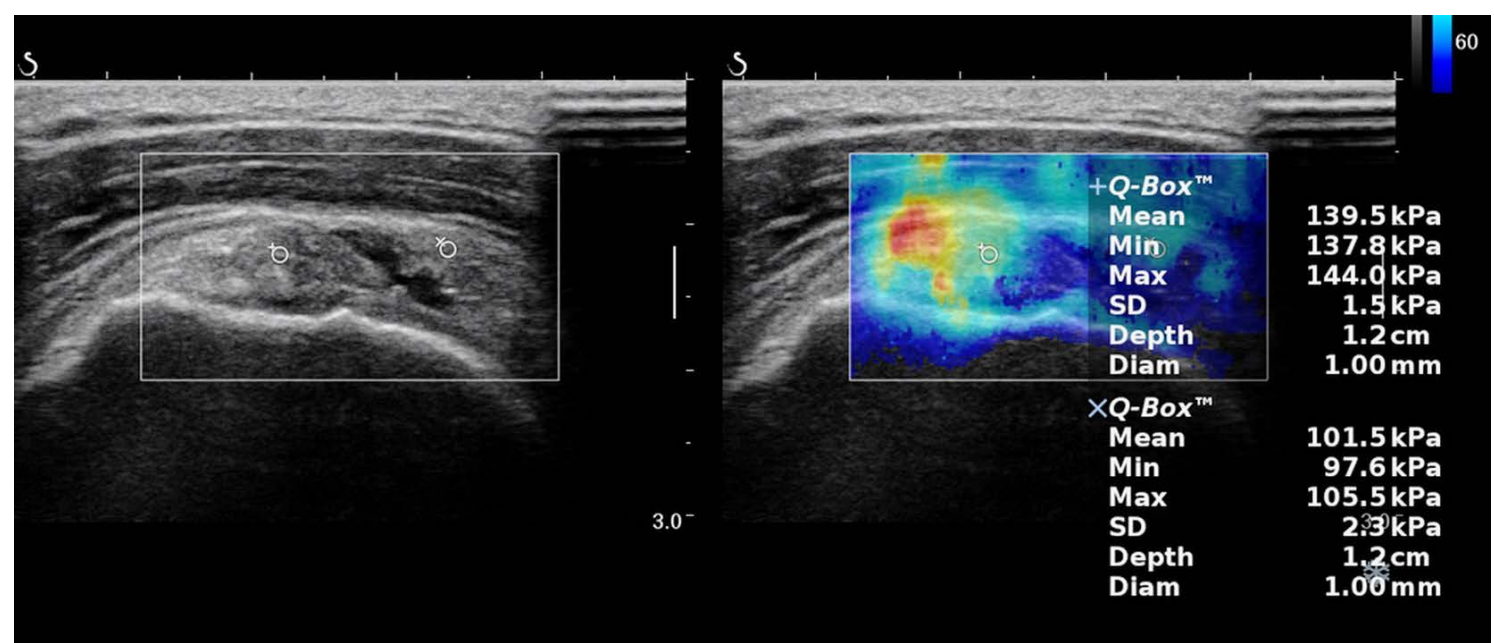

Fig. 2. A 49-year-old man suffering from right shoulder pain after a traumatic event 3 days previously. Ultrasonography shows a fullthickness tear of the right supraspinatus tendon. Elasticity was measured by shear wave elastography in the stump and the retracted portion of the torn supraspinatus tendon in a longitudinal view. 
showing an SST tear were divided depending on the interval between the onset of the symptoms and the date of the US examination, and on the presence or absence of the tangent sign on CT or MRI.

The time of onset of patients' symptoms was known for 48 of the 54 US examinations in which SST tears were identified. The interval between symptom onset and the date of the US examination was then classified into four groups: $\leq 3$ months $(n=21),>3$ months but $\leq 6$ months $(n=7),>6$ months but $\leq 1$ year $(n=12)$, and $>1$ year $(n=8)$.

Of the 52 patients with an SST tear, nine underwent MRI and three underwent $\mathrm{CT}$ of the shoulder, including a sagittal oblique view, within 2 months from the date of the US exam. Of these 12 patients, 10 showed positive tangent sign on $\mathrm{CT}$ or MRI, suggesting atrophic change of the supraspinatus muscle [14].

The data were analyzed using SPSS version 18 (SPSS Inc., Chicago, IL, USA). The Mann-Whitney U test or Kruskal-Wallis test were performed as appropriate to compare elasticity values between and among the groups. A P-value of $<0.05$ was considered to indicate a statistically significant difference.

\section{Results}

The median elasticity values and interquartile ranges (IQRs) of SSTs in various groups are summarized in Table 1.

There was no statistically significant difference in the elasticity values of SSTs between patients with a normal rotator cuff tendon (median, 94.65 kPa; IQR, 87.43 to $105.47 \mathrm{kPa}$ ) and those with torn SSTs (median, $96.79 \mathrm{kPa}$; IQR, 86.71 to $108.56 \mathrm{kPa}$; $\mathrm{P}=0.565$ ), or between patients with partial-thickness tears (median, $96.83 \mathrm{kPa}$; IQR, 90.60 to $112.20 \mathrm{kPa}$ ) and those with full-thickness SST tears (median, $93.80 \mathrm{kPa}$; IQR, 82.50 to $108.33 \mathrm{kPa} ; \mathrm{P}=0.278$ ).

When the onset of symptoms was divided into four intervals, no statistically significant difference in the elasticity values was found among the four groups $(P=0.089)$. However, a statistically significant difference in elasticity values was found when comparing 40 patients who reported having symptoms for 1 year or less (median, $92.20 \mathrm{kPa}$; IQR, 84.01 to $104.38 \mathrm{kPa}$ ) to eight patients who reported having symptoms for more than 1 year (median, $105.10 \mathrm{kPa} ; \mathrm{IQR}, 100.41$ to $116.03 \mathrm{kPa} ; \mathrm{P}=0.032$ ). Fig. 3 illustrates the case of a female patient who underwent US and SWE evaluations 2 months and 8 months after trauma to the right shoulder. A full-thickness tear of the right SST was detected on the first examination. Conservative treatment was given. The follow-up study performed 6 months later showed a more retracted SST with an increased elasticity value compared to the initial exam (Fig. 3A, B). The tear appeared anechoic on B-mode US, and the defect was shown in the color box while applying SWE (Fig. 3C).

No statistically significant difference was found when comparing elasticity values between patients with a positive tangent sign on preoperative CT/MRI (median, $92.20 \mathrm{kPa}$; IQR, 80.21 to $101.33 \mathrm{kPa}$ )

Table 1. Comparison of median elasticity values of supraspinatus tendons (SSTs) between groups classified in various ways

\begin{tabular}{|c|c|c|c|}
\hline Criteria & No. & Median elasticity, (IQR, $\mathrm{kPa})$ & P-value \\
\hline \multicolumn{4}{|c|}{ Rotator cuff tendon on B-mode ultrasonography } \\
\hline Normal & 26 & $94.65(87.43-105.47)$ & $0.565^{\mathrm{a})}$ \\
\hline SST tear present & 54 & $96.79(86.71-108.56)$ & \\
\hline \multicolumn{4}{|c|}{ Partial-thickness vs. full-thickness tears } \\
\hline Partial & 27 & $96.83(90.60-112.20)$ & $0.278^{\mathrm{a})}$ \\
\hline Full & 27 & $93.80(82.50-108.33)$ & \\
\hline \multicolumn{4}{|c|}{ Time of onset divided into 4 groups (mo) } \\
\hline$\leq 3$ & 21 & $96.37(88.83-104.39)$ & $0.089^{b)}$ \\
\hline $3-6$ & 7 & $95.10(82.50-114.27)$ & \\
\hline $6-12$ & 12 & $87.35(77.79-100.26)$ & \\
\hline$>12$ & 8 & $105.10(100.41-116.03)$ & \\
\hline \multicolumn{4}{|c|}{ Time of onset divided into 2 groups (mo) } \\
\hline$\leq 12$ & 40 & $92.20(84.01-104.38)$ & $0.032^{\mathrm{a})}$ \\
\hline$>12$ & 8 & $105.10(100.41-116.03)$ & \\
\hline \multicolumn{4}{|l|}{ Tangent sign } \\
\hline Positive & 10 & $92.20(80.21-101.33)$ & $0.485^{\mathrm{a})}$ \\
\hline Negative & 2 & $83.50(83.20-83.80)$ & \\
\hline
\end{tabular}

a) P-value by the Mann-Whitney $\mathrm{U}$ test. ${ }^{\text {b) }} \mathrm{P}$-value by the Kruskal-Wallis test. 


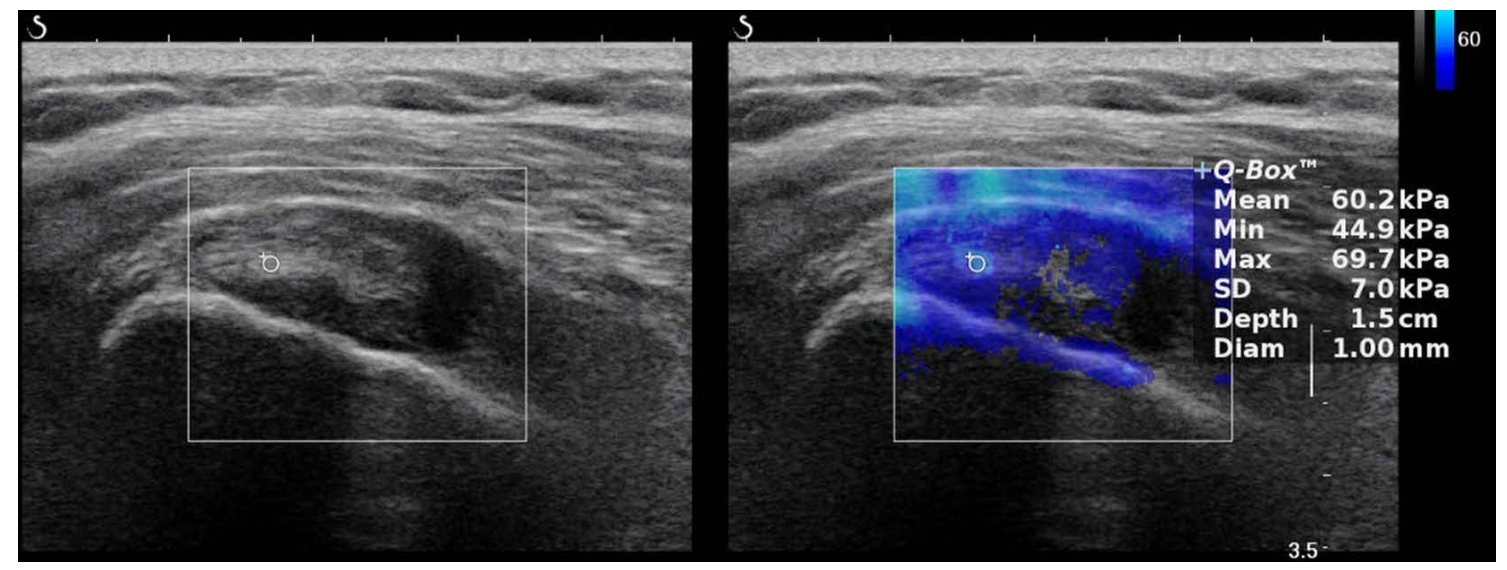

A

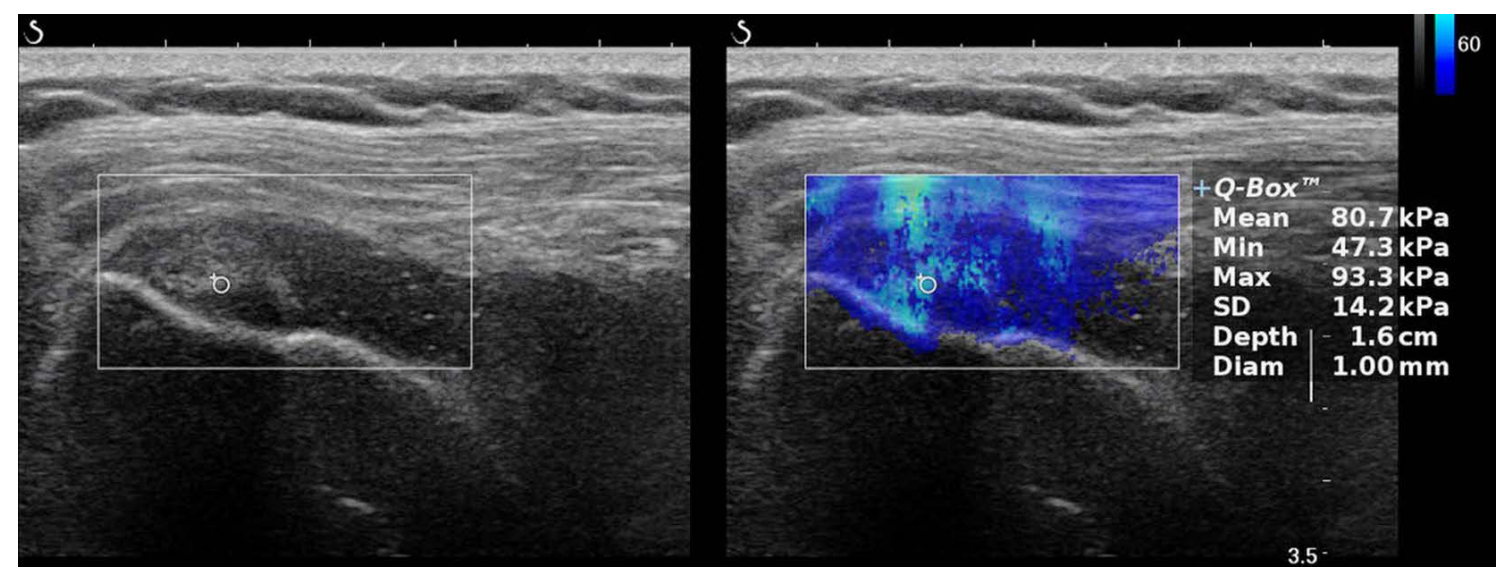

B

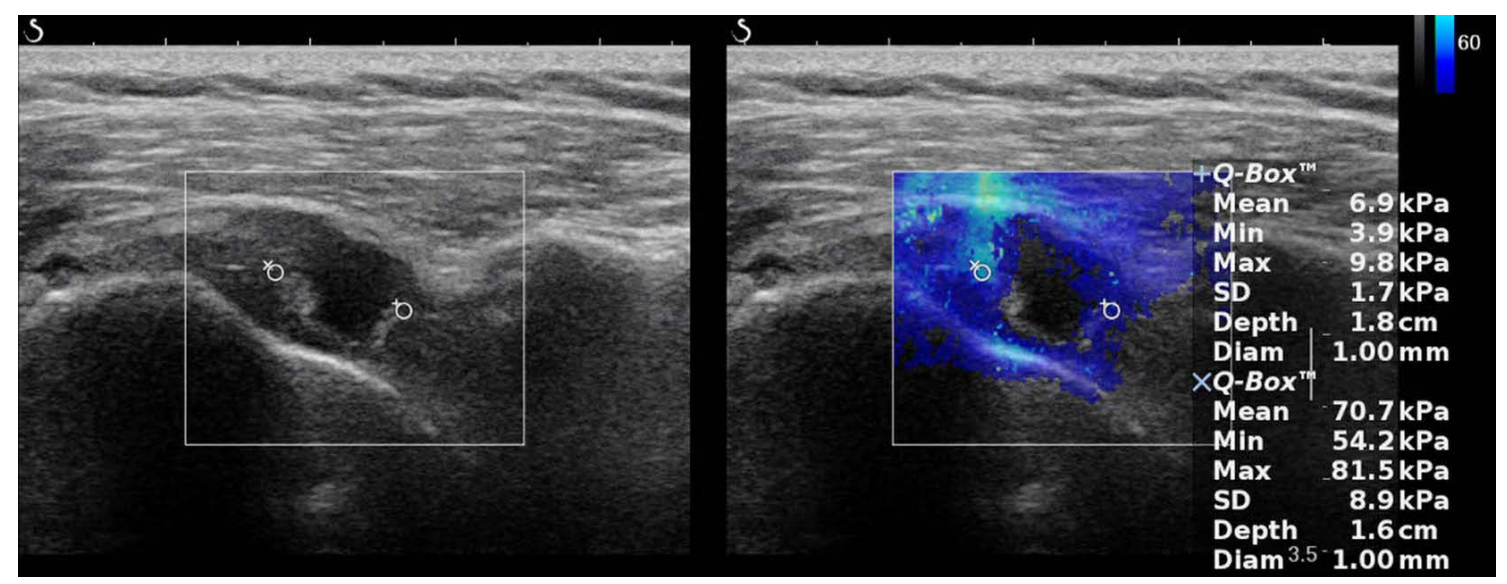

C

Fig. 3. Two ultrasound examinations with a 6-month interval in a 76-year-old woman with right shoulder pain.

$A, B$. Shear wave elastography was applied in a longitudinal scan of the supraspinatus tendon of the right shoulder in both the initial ( $A$ ) and follow-up (B) examinations performed at 2 and 8 months after trauma. Only conservative treatment was done in the interval between these examinations. A full-thickness tear was present and the elasticity value of the stump area of torn supraspinatus tendon increased from 60.2 to $80.7 \mathrm{kPa}$. C. In the follow-up study, the anechoic gap between the stump and retracted portion of supraspinatus tendon appeared as a color defect when shear wave elastography was performed. The measurement at the edge of the retracted tendon was considered to reflect contamination by joint effusion and excluded. 
and those without a tangent sign (negative tangent sign) (median, $83.50 \mathrm{kPa}$; IQR, 83.20 to $83.80 \mathrm{kPa}$; $\mathrm{P}=0.485$ ).

\section{Discussion}

The timing of surgical repair of a torn rotator cuff tendon is closely correlated with satisfactory recovery of function. A torn rotator cuff tendon loses its elasticity over time, making late surgical repair more difficult or even impossible [15]. Therefore, it is necessary to determine whether a patient is suffering from an acute or chronic rotator cuff tear prior to surgical intervention. However, it is challenging to distinguish among acute tears, acute-on-chronic tears, and chronic tears with acute symptoms, both on clinical grounds and using imaging modalities such as radiography, dynamic sonography, MRI, and arthroscopy [16].

Researchers have recently reported various ways of assessing rotator cuff tendon tears preoperatively. Nozaki et al. [17] applied 2-point Dixon MRI to rotator cuff muscles and suggested that the fat fraction observed preoperatively may offer a way to predict the recurrence of a tear after repair surgery. Rosskopf et al. [18] proposed that a preoperative evaluation of the supraspinatus muscle can help to establish a treatment plan, while measuring shear wave velocity by SWE can help to assess mechanical muscle properties and to determine the prognosis of a torn rotator cuff tendon. In our study, we measured the elasticity values of SSTs using SWE and compared them between and among groups classified in several different ways. We found significantly higher elasticity values in patients with pain for more than 1 year.

Torn tendons undergo three overlapping phases of healing: inflammation, repair, and remodeling [13]. In the inflammation phase, inflammatory cells such as erythrocytes and platelets are recruited, and phagocytosis occurs [12]. Vasoactive and chemotactic factors are released, and collagen synthesis is initiated [12]. After a few days, the repair phase begins, during which abundant collagen and extracellular matrix components are synthesized, while water and glycosaminoglycan levels remain high [12]. The remodeling phase begins approximately 6 weeks after the injury occurs and can be divided into two further stages: the consolidation stage and the maturation stage [13]. The maturation stage commences about 10 weeks after the injury and is characterized by a gradual change of fibrous tissue to scar-like tendon tissue, a process that occurs over the course of 1 year [13]. Consequently, the stiffness of the healed tendon increases [12]. In an animal study using a model of surgically created rotator cuff tears in rabbits, Hirose et al. [19] showed that a tear of $12 \mathrm{~mm}$ that included all tendinous fibers of the SST was not repaired at the third week. In contrast, when a 5-mm tear was made, reparative tissue was seen in the first week, and the defect was partially healed at the third week [19]. Based on the above healing process, the lowest elasticity value of the tendon is expected in the repair phase, which takes place within 6 weeks after the injury. However, our results showed the lowest elasticity values in the group of patients with 6-12 months of pain. A possible explanation for this finding is that patients with larger tears are more likely to be symptomatic, and larger tears are more likely to undergo delayed healing $[19,20]$. Since our study only included symptomatic patients, the healing process in our patients might have been more delayed than usual.

Our subgroup analysis revealed a significant association between elasticity values and the chronicity of symptoms, as patients with symptoms that had lasted for more than 1 year showed significantly higher elasticity values than those with symptoms that had lasted for less than 1 year. The literature contains data regarding surgical outcomes depending on symptom duration. Kim and Kim [21] claimed that a symptom duration of 12 months or longer before the arthroscopic repair of a rotator cuff tear increased the possibility of a retear. Massoud et al. [22] found significantly more unsatisfactory outcomes, such as revision surgery or aggravation of symptoms, after subacromial decompression in rotator cuff tear patients with a symptom duration longer than 12 months. While it can be difficult to determine chronicity on clinical grounds, all of these results in the literature, in combination with our findings, suggest that the presence of symptoms for 12 months may be a useful indicator when considering a surgical intervention.

Since a chronic cuff tear results in atrophy of the muscle fibers, a positive tangent sign is a widely used visual indicator of a chronic SST tear $[14,23]$. However, we found no statistically significant differences in elasticity values between the 10 cases with a positive tangent sign and the two cases without a tangent sign. This might have been due to the small sample size, especially of patients without a tangent sign.

A large difference was found in the elasticity values of normal SSTs between this study and another similar study conducted by Arda et al. [3], who found the mean elasticity value of normal SSTs to be $36.0 \pm 13.0 \mathrm{kPa}$ in men and $29.1 \pm 12.4 \mathrm{kPa}$ in women. These values are much lower than those observed in our patients with normal rotator cuff tendons, even though the same equipment was used in both studies and the patients sat in the same position [3]. There was also a large difference in the elasticity values of normal Achilles tendons between the study of Arda et al. [3] and the study of Chen et al. [7]. Although good intra- and inter-operator reproducibility of SWE has been proven for superficial tissues such as the breast [24], in a study of SWE applied to the supraspinatus muscle, Rosskopf et al. [18] reported lower reliability in deep tissues and tissue close to the bone structure. Differences in measured 
values among the studies may be due to the deep location of the tendon of interest. Furthermore, inter-operator reliability can be negatively affected by varying degrees of the force unintentionally applied by the operator during the US examination and the measurement of slightly different areas in various studies.

Our study has several limitations, some of which were related to the retrospective nature of this study. First, while the lack of surgical and histopathological correlations of the SSTs may be considered a limitation, it would be practically impossible to obtain such correlations in a real clinical setting. Second, we assessed elasticity values in patient groups divided by the duration of symptoms, assuming that a longer duration would reflect chronic tears. There are some limitations in this assumption. Some patients with a chronic SST tear may have a short duration of symptoms or no symptoms. However, the opposite would probably not be true; that is, a longer duration of symptoms should not occur in cases of acute tears. Further, it is currently difficult to determine the chronicity of SST tears clinically or even by arthroscopy before surgery [25]. This issue is probably why several other studies have also attempted to use the duration of symptoms as a criterion for classifying acute versus chronic rotator cuff tears $[26,27]$. Third, the number of patients in the subgroups classified by the onset time of symptoms was relatively small. Fourth, the objective standardization of appropriate Q-box colorization has not been previously documented. Therefore, the appropriateness of the Q-box in this study was determined by the operator. Despite these limitations, we believe that our study has provided clinically useful information. Injured tendons stiffen as they go through the healing process. We found a significant difference between the SWE-measured elasticity values of torn SSTs in patients suffering from chronic pain for more than 1 year and those of torn SSTs in patients suffering from pain for less than 1 year.

In conclusion, our study showed significantly higher elasticity values in torn SSTs in patients with chronic shoulder pain that had lasted for more than 1 year. Further studies with larger samples seem warranted to validate our results, as well as to determine whether the elasticity value measured by SWE can be used preoperatively as a surrogate marker of the chronicity of a rotator cuff tendon tear.

ORCID: Seung-Jin Yoo: https://orcid.org/0000-0002-0779-3889; Seunghun Lee: https://orcid.org/0000-0002-4348-7993; Yoonah Song: https://orcid.org/0000-00023145-5759; Chun Ki Kim: https://orcid.org/0000-0001-8048-0187; Bong Gun Lee: https://orcid.org/0000-0002-4003-5529; Jiyoon Bae: https://orcid.org/0000-00021653-9970

\section{Author Contributions}

Conceptualization: Lee S, Yoo SJ, Song Y. Data acquisition: Lee S, Yoo SJ, Song Y, Lee BG. Data analysis or interpretation: Lee S, Yoo SJ, Kim CK, Lee BG, Bae J. Drafting of the manuscript: Yoo SJ, Kim CK. Critical revision of the manuscript: Lee S, Yoo SJ, Kim CK, Lee BG. Approval of the final version of the manuscript: all authors.

\section{Conflict of Interest}

No potential conflict of interest relevant to this article was reported.

\section{References}

1. Moosikasuwan JB, Miller TT, Burke BJ. Rotator cuff tears: clinical, radiographic, and US findings. Radiographics 2005;25:1591-1607.

2. Nazarian LN, Jacobson JA, Benson CB, Bancroft LW, Bedi A, McShane JM, et al. Imaging algorithms for evaluating suspected rotator cuff disease: Society of Radiologists in Ultrasound consensus conference statement. Radiology 2013;267:589-595.

3. Arda K, Ciledag N, Aktas E, Aribas BK, Kose K. Quantitative assessment of normal soft-tissue elasticity using shear-wave ultrasound elastography. AJR Am J Roentgenol 2011;197:532-536.

4. Athanasiou A, Tardivon A, Tanter M, Sigal-Zafrani B, Bercoff J, Deffieux $T$, et al. Breast lesions: quantitative elastography with supersonic shear imaging: preliminary results. Radiology 2010;256:297-303.

5. Barr RG, Ferraioli G, Palmeri ML, Goodman ZD, Garcia-Tsao G, Rubin J, et al. Elastography assessment of liver fibrosis: Society of Radiologists in Ultrasound Consensus Conference Statement. Radiology 2015;276:845-861.

6. Samir AE, Dhyani M, Anvari A, Prescott J, Halpern EF, Faquin WC, et al. Shear-wave elastography for the preoperative risk stratification of follicular-patterned lesions of the thyroid: diagnostic accuracy and optimal measurement plane. Radiology 2015;277:565-573.

7. Chen XM, Cui LG, He P, Shen WW, Qian YJ, Wang JR. Shear wave elastographic characterization of normal and torn achilles tendons: a pilot study. J Ultrasound Med 2013;32:449-455.

8. Hsiao MY, Chen YC, Lin CY, Chen WS, Wang TG. Reduced patellar tendon elasticity with aging: in vivo assessment by shear wave elastography. Ultrasound Med Biol 2015;41:2899-2905.

9. Lashgari $C$, Redziniak $D$. The natural history of rotator cuff tears. Curr Orthop Pract 2012;23:10-13.

10. Spargoli G. Supraspinatus tendon pathomechanics: a current concepts review. Int I Sports Phys Ther 2018;13:1083-1094.

11. Abrams IS, Bell RH. Arthroscopic rotator cuff surgery: a practical approach to management. New York: Springer-Verlag, 2008.

12. Wang JH. Mechanobiology of tendon. J Biomech 2006;39:15631582.

13. Sharma P, Maffulli N. Tendon injury and tendinopathy: healing and repair. J Bone Joint Surg Am 2005;87:187-202. 
14. Zanetti M, Gerber C, Hodler J. Quantitative assessment of the muscles of the rotator cuff with magnetic resonance imaging. Invest Radiol 1998:33:163-170.

15. Lahteenmaki HE, Virolainen P, Hiltunen A, Heikkila J, Nelimarkka Ol. Results of early operative treatment of rotator cuff tears with acute symptoms. J Shoulder Elbow Surg 2006;15:148-153.

16. Mukovozov I, Byun S, Farrokhyar F, Wong I. Time to surgery in acute rotator cufftear: a systematic review. Bone Joint Res 2013;2:122128.

17. Nozaki T, Tasaki A, Horiuchi S, Ochi J, Starkey J, Hara T, et al. Predicting retear after repair of full-thickness rotator cuff tear: two-point dixon MR imaging quantification of fatty muscle degeneration-initial experience with 1-year follow-up. Radiology 2016;280:500-509.

18. Rosskopf AB, Ehrmann C, Buck FM, Gerber C, Fluck M, Pfirrmann CW. Quantitative shear-wave US elastography of the supraspinatus muscle: reliability of the method and relation to tendon integrity and muscle quality. Radiology 2016;278:465-474.

19. Hirose $K$, Kondo S, Choi HR, Mishima S, Iwata H, Ishiguro N. Spontaneous healing process of a supraspinatus tendon tear in rabbits. Arch Orthop Trauma Surg 2004;124:374-377.

20. Mall NA, Kim HM, Keener JD, Steger-May K, Teefey SA, Middleton $W D$, et al. Symptomatic progression of asymptomatic rotator cuff tears: a prospective study of clinical and sonographic variables. J Bone Joint Surg Am 2010;92:2623-2633.

21. Kim IB, Kim MW. Risk factors for retear after arthroscopic repair of full-thickness rotator cuff tears using the suture bridge technique: classification system. Arthroscopy 2016;32:2191-2200.

22. Massoud SN, Levy O, Copeland SA. Subacromial decompression. Treatment for small- and medium-sized tears of the rotator cuff. J Bone Joint Surg Br 2002;84:955-960.

23. Mendias CL, Roche SM, Harning JA, Davis ME, Lynch EB, Sibilsky Enselman $E R$, et al. Reduced muscle fiber force production and disrupted myofibril architecture in patients with chronic rotator cuff tears. J Shoulder Elbow Surg 2015;24:111-119.

24. Hong MJ, Kim HH. Intra- and interobserver reproducibility of shear wave elastography for evaluation of the breast lesions. J Korean Soc Radiol 2017;76:198-205.

25. Oh JH, Park MS, Rhee SM. Treatment strategy for irreparable rotator cuff tears. Clin Orthop Surg 2018;10:119-134.

26. Jones CK, Savoie FH 3rd. Arthroscopic repair of large and massive rotator cuff tears. Arthroscopy 2003;19:564-571.

27. Teefey SA, Middleton WD, Bauer GS, Hildebolt CF, Yamaguchi K. Sonographic differences in the appearance of acute and chronic full-thickness rotator cuff tears. J Ultrasound Med 2000;19:377378. 